\title{
Mesenteric Root
}

National Cancer Institute

\section{Source}

National Cancer Institute. Mesenteric Root. NCI Thesaurus. Code C133753.

The origin of the mesentery arising from the parietal peritoneum. 